\title{
Stimulation of Insulin Secretion Reveals Heterogeneity of Pancreatic B Cells In Vivo
}

\author{
Y. Stefan, P. Meda, M. Neufeld, and L. Orci \\ Institute of Histology and Embryology, University of Geneva Medical School, Geneva, Switzerland
}

\begin{abstract}
We examined the immunofluorescence and ultrastructural changes of insulin-producing $B$ cells in the center and at the periphery of islets of Langerhans during in vivo stimulation by glucose and glibenclamide. A decreased insulin immunostaining was detected in islets from the splenic rat pancreas after $1.5 \mathrm{~h}$ of glucose stimulation. By contrast, immunofluorescence changes became apparent in islets from the duodenal pancreas only after $>3 \mathrm{~h}$ of hyperglycemia. In both cases, the immunolabeling of central B cells decreased before that of peripheral B cells. Similar changes were seen following in vivo stimulation of insulin secretion by glibenclamide. At the ultrastructural level, hyperglycemia decreased the volume density of B cell secretory granules and increased that of rough endoplasmic reticulum and Golgi apparatus. These changes were also detected earlier in central than in peripheral $B$ cells and earlier in splenic than in duodenal islets. The data show that $B$ cells form a heterogeneous population in vivo.
\end{abstract}

\section{Introduction}

Studies on the insulin-producing B cells of the islets of Langerhans are usually performed with the implicit assumption that these cells are all alike and secrete synchronously and homogeneously under most conditions. There is, however, evidence that B cells may be structurally and functionally different. Thus, within an islet, neighboring B cells show variable amounts of secretory granules and rough endoplasmic reticulum (1) and different thresholds for glucose-induced electrical activity $(2,3)$. The findings of regional differences of $\mathbf{B}$ cells with regard to nucleus size $(4,5)$, incorporation of $\left[{ }^{3} \mathrm{H}\right]$ thymidine $(6)$, number of gap junctions (7), extent of dye coupling (8), and electrical activity $(9,10)$ further suggest that $B$ cells may be affected by the different cellular and hormonal environment they are facing in the center and at the periphery of the islets (11). However, whether these differences reflect an actual functional heterogeneity of B cells in terms of their ability to respond to insulin secretagogues remains to be established.

We have recently reported that individual B cells, exposed simultaneously to the same environment, differ in the rate at which they secrete insulin (12) and thus form a heterogeneous population in vitro. This study was undertaken to assess whether $B$ cells are also functionally heterogeneous in vivo. Furthermore, we wished to determine whether any observed heterogeneity

Address correspondence to P. Meda, M.D., Institute of Histology and Embryology, C.M.U., 1, rue Michel Servet, 1211 Geneve 4, Switzerland. Received for publication 25 November 1986 and in revised form 10 March 1987.

J. Clin. Invest.

(C) The American Society for Clinical Investigation, Inc.

0021-9738/87/07/0175/09 \$2.00

Volume 80, July $1987,175-183$ could be related to regional differences of B cell environment, within individual islets from either the duodenal or the splenic portion of the pancreas (13).

\section{Methods}

\section{Glucose infusion}

Experimental procedure. Male Sprague-Dawley (SIVZ) rats, weighing 300-350 g, were implanted with a catheter into the jugular vein. The catheter was passed subcutaneously to emerge at the top of the head and was attached on the skull using stainless steel screws and dental resin (14). Thereafter, the implanted catheter was rinsed daily with saline containing $500 \mathrm{IU}$ heparin/ml and $40 \%$ polyvinylpyrrolidone. The rats were infused 1 wk after surgery, once they had regained the control weight curve. Infusion was started by a bolus injection, via the implanted catheter, of $350 \mathrm{mg} \cdot \mathrm{Kg}^{-1}$ D-glucose (given as a $40 \%$ solution) and continued, up to the end of the experiment, by connecting the catheter to an infusion pump delivering $180 \mathrm{mg} \cdot \mathrm{Kg}^{-1} \cdot \mathrm{min}^{-1}$ glucose (given as a $20 \%$ solution). Controls received similar volumes of saline. Throughout the experiment, all rats had free access to water and food and could move freely within their cage. Before starting the infusion and periodically throughout it, blood samples were taken at the tail of each rat for measurement of plasma glucose and insulin, by the glucose oxidase method and a radioimmunoassay with a charcoal separation step, respectively.

Islets of Langerhans were isolated from the pancreas of 8 control and 12 glucose-infused rats after $1.5,3,12$, and $24 \mathrm{~h}$ of infusion, using collagenase digestion (15) and purification on Ficoll gradients (16). In each animal, the lower third of the pancreas head was dissected separately from the rest of the gland and the two portions were processed in parallel to isolate "duodenal" and "splenic" islets, respectively (13). Both islet types were isolated and collected in 50-60 min and then immediately fixed in a $2.5 \%$ glutaraldehyde solution in $0.1 \mathrm{M}$ phosphate buffer. Subsequently, the islets were postfixed in $1 \%$ osmium tetroxyde and processed for conventional electron microscopy according to standard procedures. The duodenal and splenic pancreas of six other rats (one control and five glucose-infused) were fixed in Bouin's solution at the end of the infusion and processed for light microscopy according to standard procedures.

Immunofluorescence. 5- $\mu \mathrm{m}$-thick sections cut in the duodenal and splenic pancreas of control and glucose-infused rats were processed for indirect immunofluorescence, as previously described (17). The following antisera and dilutions were used: guinea pig antiinsulin (Dr. P. H. Wright, Indianapolis, IN), 1:200; rabbit antisomatostatin (Dr. M. P. Dubois, Nouzilly, France), 1:100; rabbit antipancreatic polypeptide (Dr. R. E. Chance, Indianapolis, IN), 1:1,000; rabbit antiglucagon (Dr. L. Heding, Copenhagen, Denmark), 1:100. Each section was incubated for $2 \mathrm{~h}$ at room temperature with one of these antisera, rinsed in phosphate-buffered saline (PBS), and then exposed to a fluorescein-labeled serum against either guinea pig (Nordic Immunological Laboratories, Tilburg, The Netherlands) or rabbit IgG (Tago Inc., Burlingame, CA), both diluted $1: 20$, for $1 \mathrm{~h}$ at room temperature. Sections were rinsed, counterstained with $0.01 \%$ Evans blue, coverslipped in $25 \%$ glycerin in PBS, and observed for fluorescence in a Leitz Orthoplan microscope (Leitz Wetzlar, FRG) equipped with a Ploemopak condenser.

Quantitative electron microscopy. Two to three rats and five splenic and duodenal islets per rat were studied in each group. Thin sections were cut in the equatorial region of large (diameter $\geqslant 200 \mu \mathrm{m}$ ) islets, stained with uranyl acetate and lead citrate, and examined with a EM300 

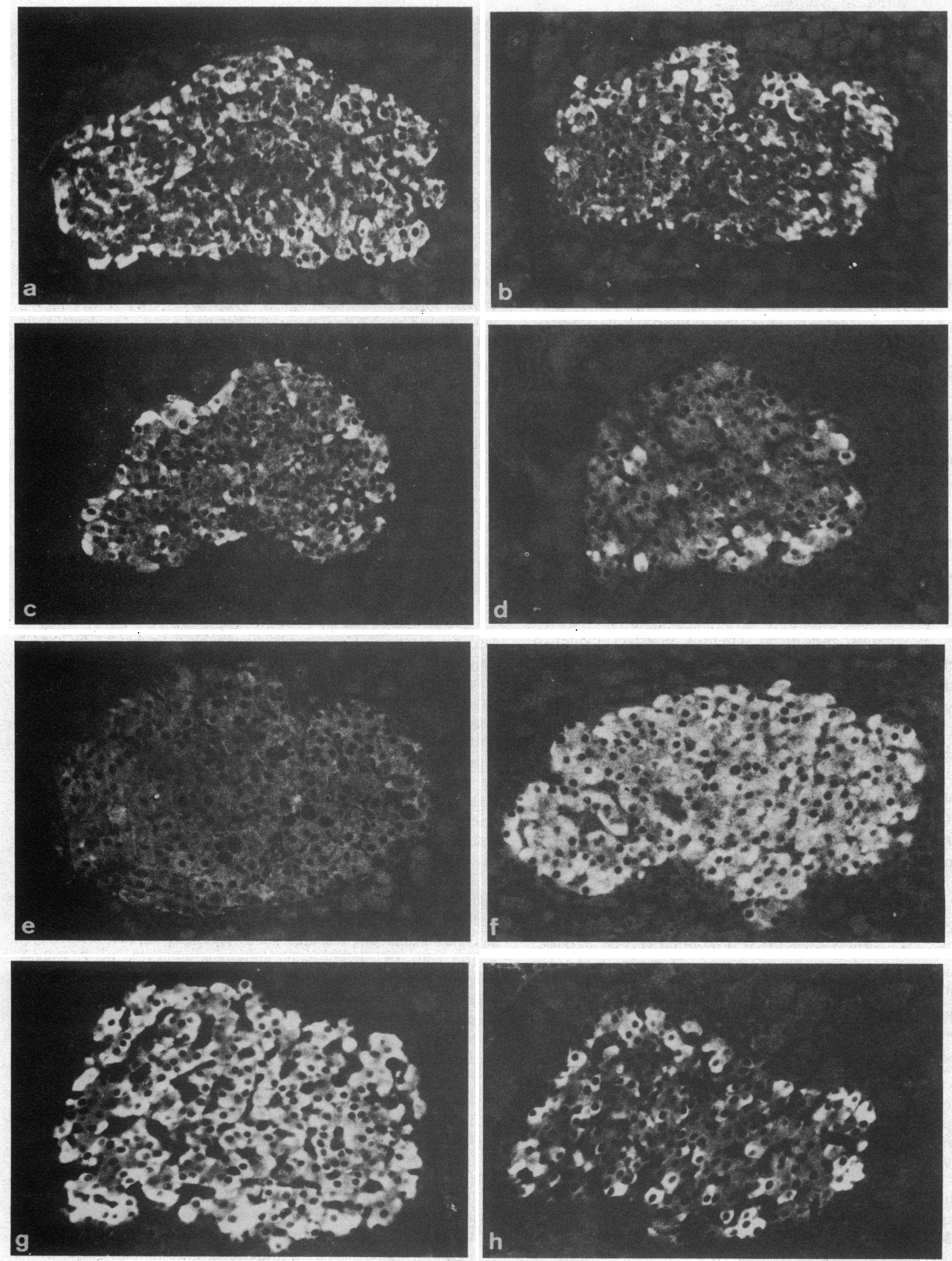
electron microscope (Philips Electronic Instruments, Inc., Mahwah, NJ). $B$ cells were analyzed morphometrically in the center and at the periphery of each islet, the limit between the two zones being determined by the position of islet sections with respect to the bars of the supporting grid (7). In the peripheral islet region, B cells were considered "peripheral" if they were seen to contact at least one non-B cell (Figs. $2 A$ and $3 A$ ). In the central islet region, $B$ cells were considered "central" whenever they were surrounded only by other B cells (Figs. $2 B$ and $3 B$ ).

A total of $\sim 100$ and $600 \mathrm{~B}$ cells were scored per animal and per group, respectively. This sample gave cumulative standard errors representing $<5-10 \%$ of the mean estimate of each parameter and thus was considered representative of the native $B$ cell population (18).

B cell organelles were identified on electron micrographs according to standard criteria (1). Single membrane-bound profiles were attributed to beta-secretory granules whenever they showed a pale or dark core. Thus, no distinction was made between the granules with a tightly fitting core and those with a clear halo, nor between coated and uncoated granules. Golgi apparatus was evaluated by outlining the area occupied by the stacks of cisternae and their related vesicles. Rough endoplasmic reticulum (RER) ${ }^{1}$ was evaluated as the area encompassing flattened cisternae and vesicles bearing ribosomes, together with the little cytoplasm between them.

For the evaluation of nuclear-to-cytoplasm ratio, one photograph per cell was taken at the original magnification of $2,000 \times$. For the evaluation of RER, Golgi apparatus, and secretory granule volumes, two opposite regions of each $B$ cell were photographed at the original magnification of $8,600 \times$. For all compartments, point counting was performed on negatives enlarged 4.5 times by projection on a screen fitted with a coherent double quadratic lattice test system (lattice point ratio, 99:981) and volume density was calculated according to formula 4.1 of reference 18. Volume density values were normally distributed for all organelles and thus were expressed as mean \pm SEM and compared using an unpaired Student's $t$ test.

\section{Glibenclamide treatment}

Experimental procedure. Rats were either injected once i.p. with 2 $\mathrm{mg} \cdot \mathrm{Kg}^{-1}$ glibenclamide $(7,19)$ and sacrificed 2,6 , and $12 \mathrm{~h}$ later, or received two injections of the drug with a 12-h interval and were sacrificed $24 \mathrm{~h}$ after the beginning of the treatment. Noninjected rats served as control. The effects of each treatment were followed by measuring glucose and insulin plasma levels and insulin content of pancreatic fragments, as described above. At the end of each treatment, the duodenal and the splenic portion of each pancreas were dissected separately (13), fixed in Bouin's solution and processed for immunohistological staining as described above.

Quantitative immunofluorescence. 20-40 duodenal and splenic islets from three to five rats were evaluated for each time point. This sample gave cumulative standard errors representing $<5-10 \%$ of the mean estimates and thus was considered representative of the native islet population (18). The B cell response was followed by quantitating the changes of insulin immunostaining known to reflect mostly changes in the content of secretory granules. To this end, the volume density of immunolabeled B cells was established by point counting on equatorial islet sections, all fluorescent B cells being scored as positive, irrespective of the intensity of their immunostaining, at the periphery and in the center of each islet. The limit between these two regions was arbitrarily established at $\mathbf{3 0}$

1. Abbreviation used in this paper: RER, rough endoplasmic reticulum. $\mu \mathrm{m}$, i.e., $\sim 3$ cell diameters from the perimeter of the B cell mass. Point counting was performed on color slides projected at the final magnifcation of 750 using a coherent double quadratic lattice test system (lattice point ratio, 64:756). Volume density was calculated according to the equation reported in reference 17 , to correct for the overestimation of volume density of fluorescent B cells. Volume densities were expressed as mean \pm SEM and compared using an unpaired Student's $t$ test.

\section{Results}

Glucose stimulation. At the beginning of the experiment, plasma glucose $(128 \pm 3 \mathrm{mg} \%)$ and insulin $(4.5 \pm 0.4 \mathrm{ng} / \mathrm{ml})$ were similar in all rats ( $n=2-3$ in each group). Glycemia remained unchanged throughout the saline infusion of controls. By contrast, it increased rapidly in the rats infused with glucose. Thus, after $15 \mathrm{~min}$ of this infusion, glycemia was elevated $(P<0.001) 2.2-$ 2.6-fold over control value and remained at least at that level up to the end of the experiment. At sacrifice, blood glucose was $249 \pm 8 \mathrm{mg} \%, 319 \pm 51 \mathrm{mg} \%, 400 \pm 38 \mathrm{mg} \%$, and $482 \pm 28 \mathrm{mg} \%$ in the rats infused with glucose for $1.5,3,12$, and $24 \mathrm{~h}$, respectively. Plasma insulin was also markedly increased during glucose infusion. At the end of the experiment, insulinemia was 20.2 \pm 8.7 $\mathrm{ng} / \mathrm{ml}, 26.2 \pm 15.0 \mathrm{ng} / \mathrm{ml}, 38.3 \pm 4.7 \mathrm{ng} / \mathrm{ml}$, and $18.3 \pm 1.1 \mathrm{ng} / \mathrm{ml}$ in the rats infused with glucose for $1.5,3,12$, and $24 \mathrm{~h}$, respectively. These values represented a 5-15-fold increase $(P<0.001)$ over control levels.

After immunostaining of pancreas for insulin, fluorescent B cells were homogeneously distributed throughout the large (diameter, $\geqslant 200 \mu \mathrm{m}$ ) islets of normoglycemic rats (Fig. $1 F$ ). By contrast, in glucose-infused rats, fluorescent $B$ cells rapidly became less abundant in the center of these microorgans (Fig. 1, $A-D$ ). Up to the 12 th hour of infusion, this change was more evident in splenic (Fig. 1, B-D) than in duodenal islets (Fig. 1, $A$ and $C$ ). (Analogous changes were detected later in smaller [diameter, 30-100 $\mu \mathrm{m}$ ] islets.) Thereafter, the difference between central and peripheral $B$ cells and between splenic and duodenal islets was no longer detectable, most B cells being virtually unstainable within large islets (Fig. $1 E$ ). At this time, however, the sparce extrainsular B cells and the non-B cells of the outermost islet layers were still clearly immunolabeled by their respective specific antisera (not shown).

At the electron microscope level, the cytoplasmic organization of B cells of normoglycemic rats (all animals at the beginning of the experiment and throughout saline infusion) corresponded to that described in noninfused controls (1) and appeared similar in the center and at the periphery of both splenic and duodenal islets. During glucose infusion, B cells became progressively less granulated and showed enlarged RER and Golgi apparatus. These changes were detected earlier in central (Figs. $2 B$ and $3 B$ ) than in peripheral $B$ cells (Figs. $2 A$ and 3 $A$ ) and earlier in splenic than in duodenal islets. Thus, a decrease of secretory granules was seen in central B cells of splenic islets by $1.5 \mathrm{~h}$ of glucose infusion and was marked after $3 \mathrm{~h}$ of stim-
Figure 1. Immunostaining of pancreatic sections for insulin after various periods of glucose infusion $(A-F)$ or glibenclamide treatment $(G$ and $H$ ). In controls, the immunofluorescent B cells were evenly distributed throughout the islets $(F)$. After $3 \mathrm{~h}$ of glucose infusion $(A$ and $B)$, the labeling was unchanged at the periphery of the islets but decreased in the center of the microorgans. This regional difference was more apparent in splenic $(B)$ than in duodenal islets $(A)$ and became more accentuated with time. After $6(C)$ and $12 \mathrm{~h}$ of infusion $(D)$, the few $B$ cells still immunostainable in splenic islets were mostly located at their periphery. After $24 \mathrm{~h}$ of infusion, virtually no B cell was still labeled by the specific antiserum used $(E) .(G)$ and $(H)$ show the immunostaining of B cells after $6 \mathrm{~h}$ of glibenclamide treatment. Central B cells are less stained than peripheral B cells in splenic $(H)$ but not duodenal islets $(G)$. Bar represents $50 \mu \mathrm{m}$. 


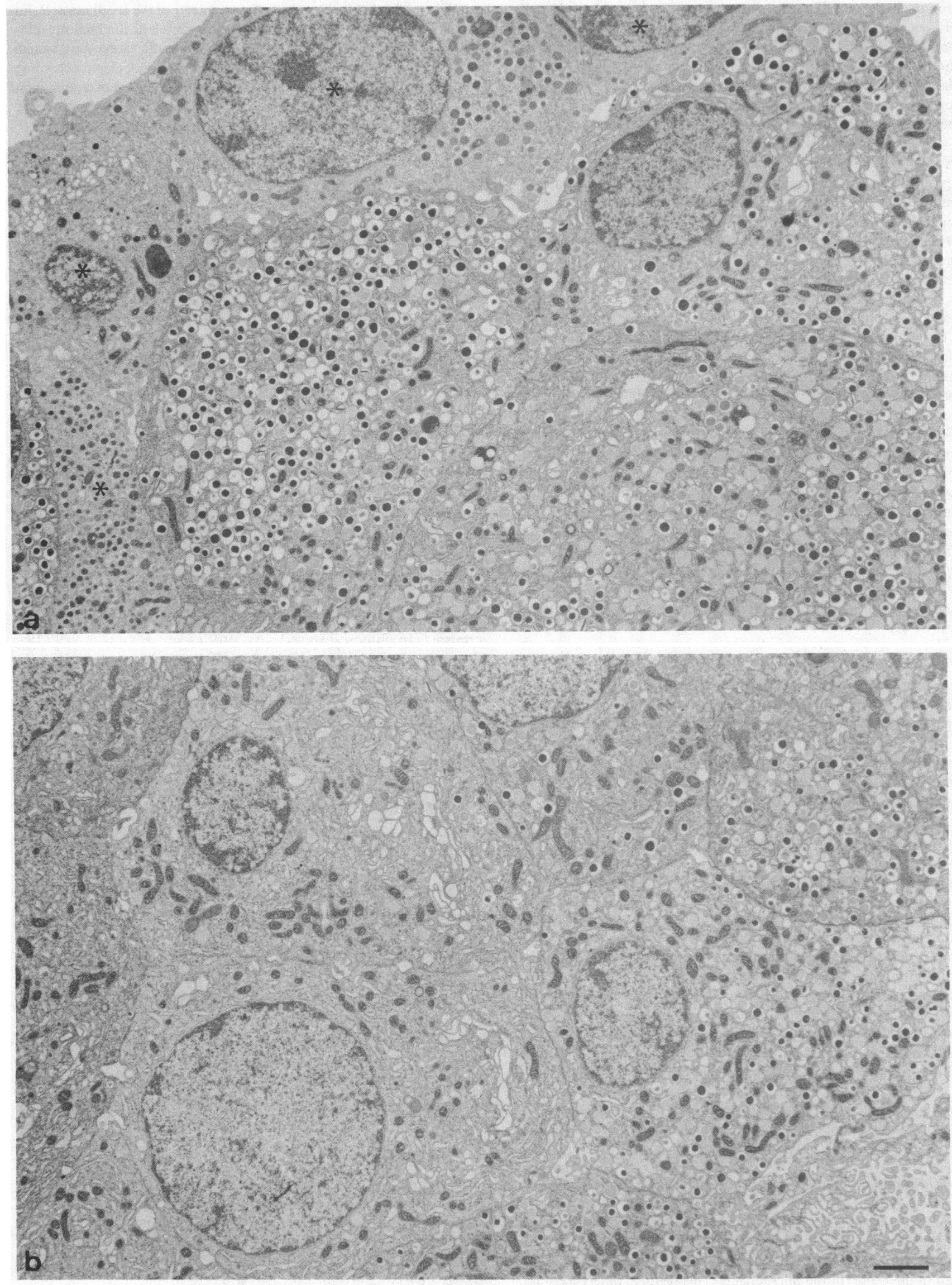


ulation (Fig. 2 B), whereas it became obvious in peripheral Bcells only after $12 \mathrm{~h}$ of stimulation (Fig. $3 \mathrm{~A}$ ). The difference between central and peripheral $B$ cells was no longer detectable after $24 \mathrm{~h}$ of glucose infusion, when most B-cells were degranulated throughout the islets (Fig. 3, $A$ and $B$ ).

The response of $B$ cells to secretagogues was evaluated by quantitating the volume density of RER, Golgi apparatus, and secretory granules. (The volume density of nucleus was similar in central and peripheral B cells of both splenic and duodenal islets and, unlike the volume density of the other organelles, remained unchanged under all conditions studied [average for the 1935 B-cells studied was $0.262 \pm 0.03]$.) Fig. 4 shows the average values of these parameters which were computed for the entire B cell population. Because volume densities were not affected by the duration of the saline infusion (not shown), a single control group was made by pooling data from all normoglycemic rats. In this control group, secretory granules, Golgi apparatus, and RER represented 20,7 , and $13 \%$ of the cytoplasmic B cell volume, respectively. Glucose stimulation decreased the volume density of B cell granules as a function of time. Thus, after 1.5, 3,12 , and $24 \mathrm{~h}$ of infusion, the relative volume of granules was decreased $(P<0.001)$ by $22,25,57$, and $91 \%$ as compared with control value, respectively (Fig. 4). This change was associated with a parallel increase $(P<0.001)$ in the volume density of RER (Fig. 4). The volume density of the Golgi apparatus compartment also increased during glucose stimulation, reaching statistical significance $(P<0.001)$ after $3 \mathrm{~h}$ of infusion (Fig. 4). Regression analysis revealed a significant $(P<0.002)$ inverse linear correlation between the relative volumes of granules and of either RER $(r=-0.99)$ or Golgi $(r=-0.98)$ compartments.

Comparison of the data from peripheral $B$ cells did not reveal differences between splenic and duodenal islets, under both control and glucose-stimulated conditions (not shown). By contrast, central B cells showed a lower $(P<0.001)$ volume density of secretory granules in splenic than in duodenal islets (Fig. 5). This difference increased $(P<0.001)$ during the first $3 \mathrm{~h}$ of stimulation (Fig. 5) but was no more apparent after 12 and 24 $h$ of glucose challenge.

In both splenic and duodenal islets, the glucose-induced changes were detected much earlier in central than in peripheral B cells. As seen in Fig. 6, which summarizes the data for the entire islet population, the volume density of secretory granules was already decreased $(P<0.001)$ in central B cells after $1.5 \mathrm{~h}$ of glucose stimulation, whereas in peripheral B cells, it changed only from the third hour of glucose infusion onward. Similarly, the volume density of RER and of Golgi apparatus increased first in central B cells and later in peripheral B cells (Fig. 6).

Glibenclamide stimulation. Glibenclamide decreased transitorily plasma glucose to 47 and $67 \%$ of control value (109 \pm 8 $\mathrm{mg} \%$ ) after the first 2 and $6 \mathrm{~h}$ of treatment, respectively. Glycemia returned then to control level until the end of the experiment. At that time, the plasma insulin level $(5.3 \pm 0.7 \mathrm{ng} / \mathrm{ml})$ was similar to that of controls. By contrast, the insulin content of both splenic and duodenal fragments was rapidly decreased $(P<0.001)$ by the glibenclamide treatment. Thus, $70 \pm 4,76 \pm 10,35 \pm 2$, and
$26 \pm 2 \mu \mathrm{g}$ of insulin per gram of pancreas were measured after 2 , 6,12 , and $24 \mathrm{~h}$ of glibenclamide treatment, respectively. The latter value represented $17 \%$ of the control insulin content (153 $\pm 11 \mu \mathrm{g}$ of insulin per gram of pancreas).

After immunostaining for insulin, B cells of control pancreas were intensely fluorescent in the center and at the periphery of both duodenal and splenic islets. $2 \mathrm{~h}$ after the first glibenclamide injection, $B$ cell fluorescence appeared unchanged in duodenal islets whereas it was noticeably decreased in the center of splenic islets (not shown). The difference between central and peripheral $B$ cells and between duodenal (Fig. $1 G$ ) and splenic islets (Fig. $1 H$ ) increased with time. One day after the onset of treatment, the few B cells that were still immunostainable were more numerous in duodenal than in splenic islets and, within the latter microorgans, predominated in the peripheral layers (not shown).

Quantitative evaluation showed that the volume density of immunostained B cells, which reflects mostly their content in secretory granules, was similar throughout splenic and duodenal control islets (Fig. 7). During glibenclamide stimulation, the volume density of fluorescent $B$ cells decreased faster $(P<0.001)$ in splenic than in duodenal islets (Fig. 7). Whereas in splenic islets this decrease was larger $(P<0.001)$ for central than for peripheral B cells, such a difference was not observed in duodenal islets (Fig. 7).

\section{Discussion}

We have shown that, upon in vivo stimulation by either glucose or glibenclamide, the main organelles involved in the biosynthesis, processing, storage, and release of insulin undergo changes at different rates, depending on the location of $\mathbf{B}$ cells within the islets and on the location of the islets within the pancreas. These observations indicate that B cells show a regional heterogeneity in vivo in terms of their ability to respond to stimulation by insulin secretagogues.

The morphometric parameters considered to reflect the response of B cells to stimulation were the volume density of betasecretory granules, RER, and Golgi apparatus as well as that of $B$ cells immunolabeled with an antiinsulin serum. These parameters changed during the sustained stimulation of insulin secretion induced by glucose and glibenclamide. Thus, the relative volume of secretory granules decreased with time whereas that of RER and Golgi apparatus increased, in a way consistent with the secretagogue-induced stimulation of granule exocytosis (1921) and islet protein biosynthesis (22-24), respectively. There is also evidence that splenic islets have higher rates of stimulated insulin secretion and biosynthesis than duodenal islets (25-27). Accordingly, morphometric analysis detected changes of B cell organelles first in splenic and then in duodenal islets, therefore extending to in vivo situations the in vitro findings that islet heterogeneity is, at least in part, related to the differential distribution of the microorgans within the pancreas.

Nevertheless, the unique advantage of morphometry was to further reveal the heterogeneity of B cells located in different
Figure 2. Ultrastructural appearance of isolated islets after $3 \mathrm{~h}$ of glucose infusion. In spite of sustained hyperglycemia, the B cells located at the periphery of the islets $(A)$ appear similar to those of normoglycemic controls. The non-B cells of the outermost islet layer (asterisk) are also unaffected. In contrast, several B cells are already markedly degranulated in the center of splenic islets $(B)$. In the latter cells, RER, Golgi apparatus, and mitochondria are the most prominent organelles. Bar represents $0.5 \mu \mathrm{m}$. 

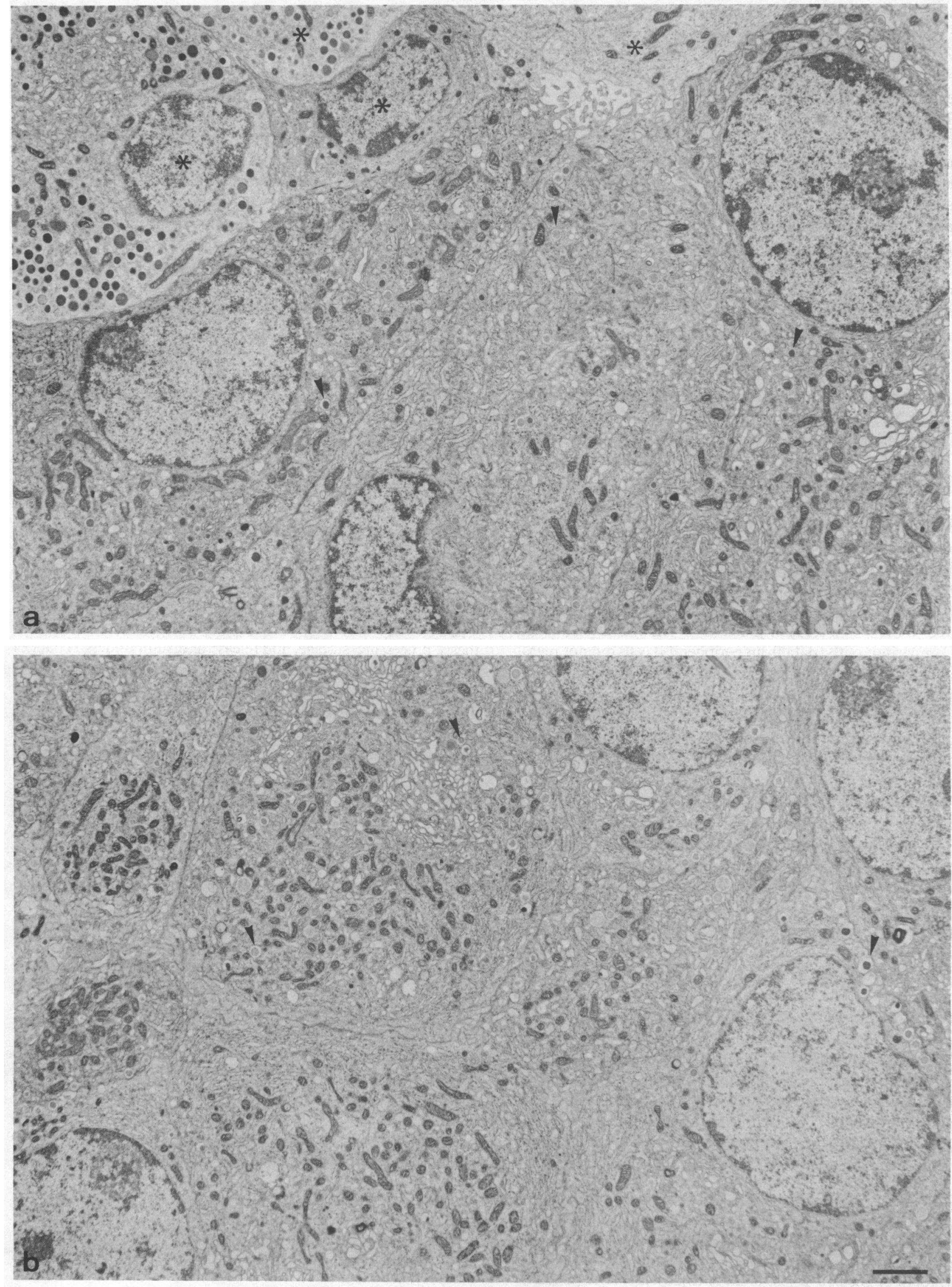

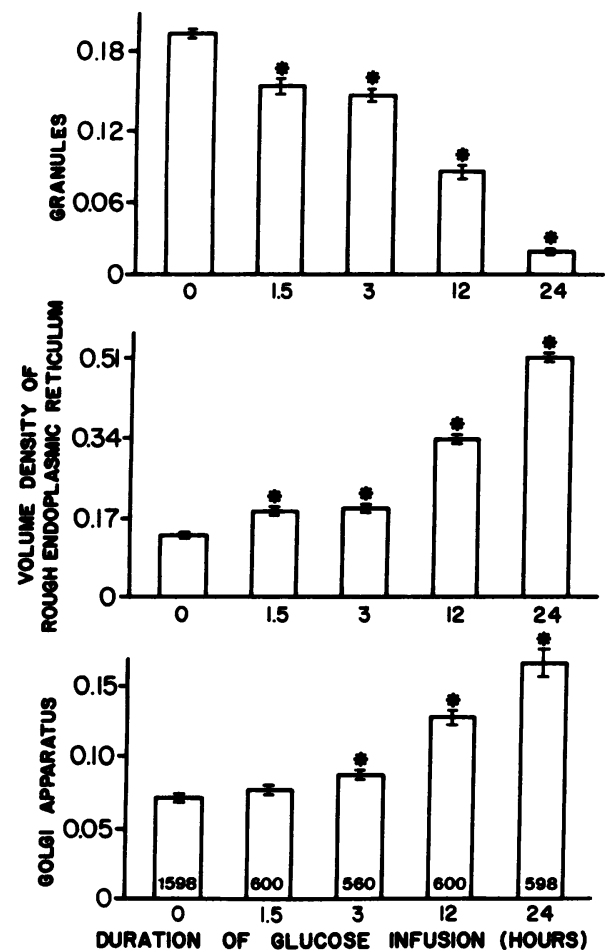

Figure 4. Volume density of organelles involved in the biosynthesis, processing, storage, and release of insulin within pancreatic B cells. Values (mean \pm SEM) were obtained by pooling data from central and peripheral B cells of both splenic and duodenal islets. The number of photographs evaluated is shown inside the columns. Asterisks indicate significant $(P<0.001)$ differences between control and glucose-infused groups.

regions of the islets. ${ }^{2}$ Thus, short-term stimulation by either glucose or glibenclamide affected essentially the B cells located in the center of the islets, whereas the B cells located at the islet periphery appeared modified only after prolonged secretagogue challenge. These data suggest that central B cells may account for most of the insulin secreted during acute secretagogue challenge, whereas peripheral B cells may significantly contribute to the total insulin output only after a long period of sustained stimulation. This difference in B cell functioning has hitherto escaped detection by biochemical approaches which cannot distinguish the contribution of $B$ cells from different islet regions to the overall response of an intact pancreas or islet.

The factor(s) involved in the different response of B cells in

2. It is most unlikely that this heterogeneity is an artefactual result of islet isolation because it was not detected in two groups of islets (controls and duodenal islets infused with glucose for $1.5 \mathrm{~h}$ ) isolated with the very same procedure and collagenase batch used for all other groups and because it was readily observed in glucose- and glibenclamide-stimulated islets immunostained in situ after immersion fixation of the whole intact pancreas.
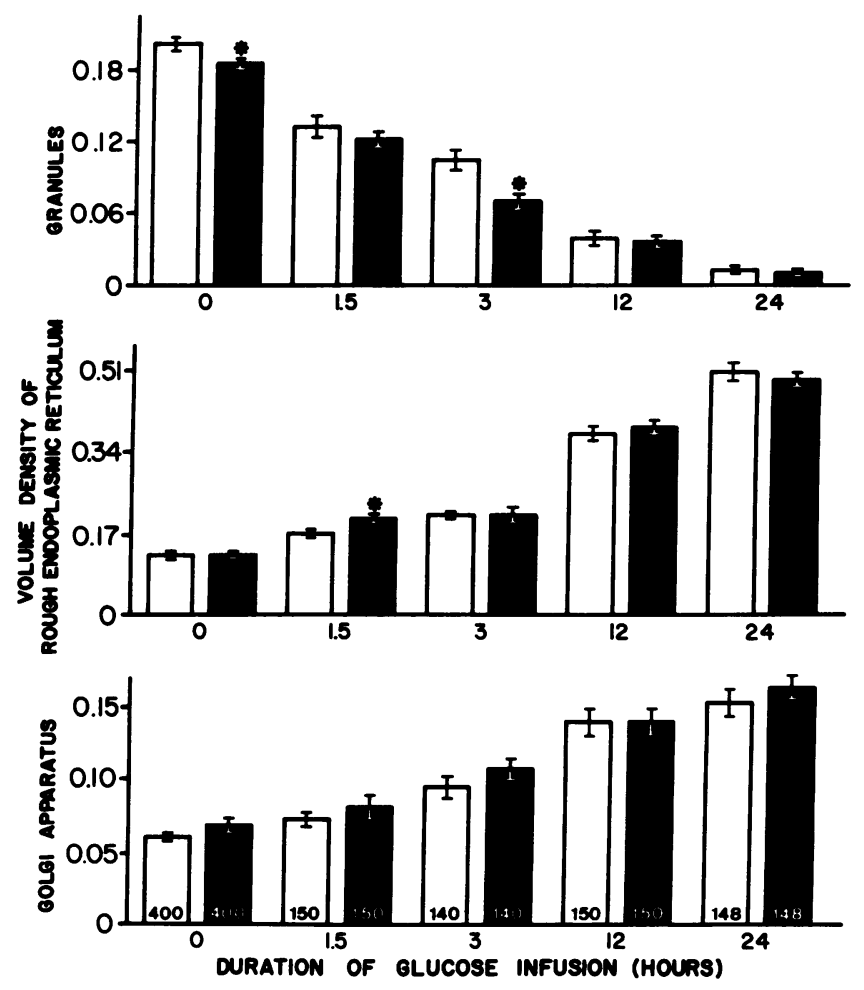

Figure 5. Volume density of organelles involved in the biosynthesis, processing, storage, and release of insulin within pancreatic B cells. Values (mean \pm SEM) were obtained from central B cells of either duodenal (open columns) or splenic islets (solid columns). The number of photographs evaluated is shown inside the columns. Asterisks indicate significant $(P<0.01-0.001)$ differences between duodenal and splenic islets.

the center and at the periphery of the islets are still hypothetical. Central and peripheral B cells face a different cellular (11) and, likely, hormonal (11) and ionic (10) environment and are not similarly coupled through gap junctions $(7,8,28)$, all differences which could conceivably account for their differential modulation. Furthermore, central and peripheral B cells appear also to have different relationships with the microvasculature and the autonomic innervation of the islets. Thus, even though there is still disagreement as to whether afferent arterioles branch to supply capillaries first to the periphery and then to the core of rat islets $(29,30)$ or vice versa $(31)$, it is now generally agreed that some B cells are directly bathed by the systemic circulation whereas others receive blood that has passed through, and possibly has been modified by, a different islet region (29-33). It is also established now that the islets of Langerhans are richly supplied with autonomic innervation and that cholinergic, adrenergic, and peptidergic nerve endings contact the insulin-producing B cells (33-35). Although the distribution of these contacts has yet to be determined quantitatively, reports have suggested a higher density of nerve terminals among peripheral islet cells $(34,35)$. In view of the participation of blood flow and

Figure 3. Ultrastructural appearance of isolated islets after $24 \mathrm{~h}$ of glucose infusion. At this time, most B cells are extensively degranulated at the periphery $(A)$ as well as in the center $(B)$ of the islets. Rare beta-secretory granules (arrowheads) are recognized in their cytoplasm. Note that the non-B cells of the islet periphery $(A)$ appear unaffected. Bar represents $0.5 \mu \mathrm{m}$. 

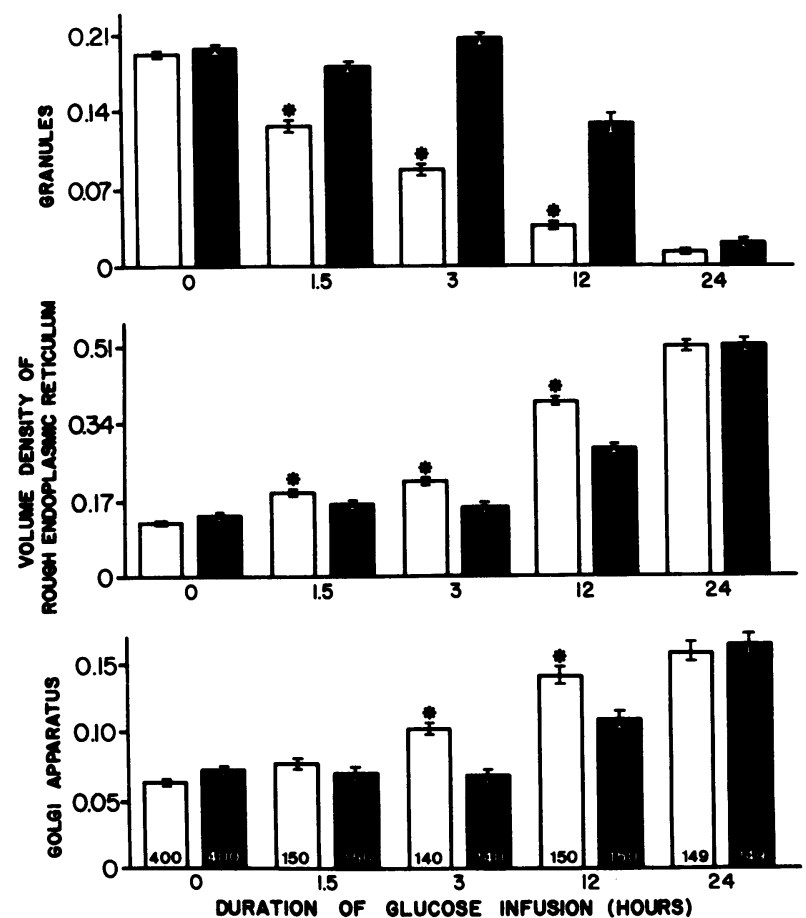

Figure 6. Volume density of organelles involved in the biosynthesis, processing, storage, and release of insulin within pancreatic B cells. Values (mean \pm SEM) for both central (open columns) and peripheral B cells (solid columns) were obtained by pooling data from splenic and duodenal islets. The number of photographs evaluated is shown inside the columns. Asterisks indicate significant $(P<0.01-0.001)$ differences between central and peripheral $B$ cells.

neurotransmitters in the control of insulin secretion $(32,33)$, these regional differences could well be also implicated in the functional heterogeneity of central and peripheral B cells. At present, however, our results do not exclude the existence of intrinsic differences between $B$ cells. Evidence that apparently alike $B$ cells secrete at widely different rates when exposed simultaneously to the same environment has indeed been obtained in vitro (12).

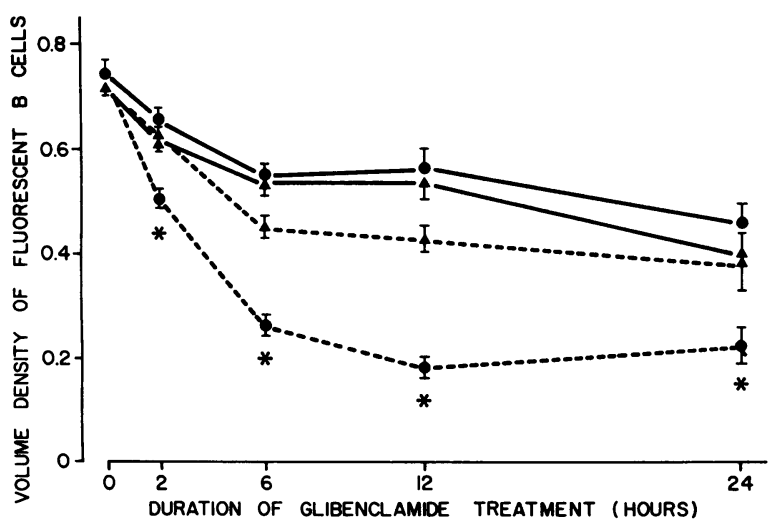

Figure 7. Volume density of fluorescent B cells, reflecting mostly their content in secretory granules, evaluated on pancreatic sections after immunostaining with a specific antiinsulin serum. For each time point, values for central $(\bullet)$ and peripheral B cells $(\Delta)$ are mean \pm SEM of measurements made in 22-40 duodenal (solid line) or splenic islets (dotted line). Asterisks indicate significant $(P<0.001)$ differences between central and peripheral $B$ cells of splenic islets.
The physiological implications of the different time course and rate of insulin secretion from central and peripheral B cells remain also to be established. The observation that insulin is secreted in a nonrandom fashion from at least two compartments has suggested the existence of subpopulations of either betasecretory granules or B cells, differing in their sensitivity to secretagogues (36-39). At this stage, we have provided evidence that subpopulations of B cells that differ in their ability to respond to physiological and pharmacological insulin secretagogues indeed exist in distinct, recognizable regions of the islets of Langerhans.

\section{Acknowledgments}

We thank Dr. E. Trimble and Dr. C. Wollheim for insulin measurements, Dr. A. Perrelet for comments on the manuscript, and Mrs. D. Ben Nasr, A. Charollais, F. Fichard-Gribi, and P. Ruga, as well as Mr. P. A. Ruttiman, for technical assistance.

This work was supported by grants 3.460 .83 and 3.404 .86 from the Swiss National Science Foundation and by the National Institutes of Health grant 5RO1-AM-30519-02 (to Dr. Meda).

\section{References}

1. Orci, L. 1974. A portrait of the pancreatic B-cell. Diabetologia. 10:163-187.

2. Beigelman, P. M., B. Ribalet, and I. Atwater. 1977. Electrical activity of mouse pancreatic beta-cells. II. Effects of glucose and arginine. J. Physiol. (Paris). 73:201-217.

3. Mathews, E. K., and P. M. Dean. 1970. Electrical activity in islet cells. In Structure and Metabolism of Pancreatic Islets. S. Falkmer, B. Hellman, and I.-B. Taljedal, editors. Cambridge University Press, Cambridge. 305-313.

4. Hellerström, C., B. Peterson, and B. Hellman. 1960. Some properties of the B-cells in the islets of Langerhans studied with regard to the position of the cells. Acta Endocrinol. 34:449-456.

5. Hellman, B., and C. Hellerström. 1959. Size differences of the Bcell nuclei in the islet tissue of normal and alloxan-treated rats. Acta Pathol. Microbiol. Scand. 45:113-121.

6. Hellerström, C., B. Hellman, S. Brolin, and S. Larson. 1962. In vitro incorporation of thymidine-H3 in the pancreas of normal and obesehyperglycemic mice. Acta Pathol. Microbiol. Scand. 54:1-8.

7. Meda, P., J.-F. Denef, A. Perrelet, and L. Orci. 1980. Non-random distribution of gap junctions between pancreatic B-cells. Am. J. Physiol. 238:C114-C119.

8. Michaels, R. L., and J. D. Sheridan. 1981. Dye coupling among immunocytochemically distinct cell types. Science (Wash. DC). 214:801803.

9. Meda, P., I. Atwater, A. Goncalves, A. Bangham, L. Orci, and E. Rojas. 1984. The topography of electrical synchrony among B-cells in the mouse islet of Langerhans. Q. J. Exp. Physiol. 69:719-735.

10. Perez-Armendariz, E., I. Atwater, and E. Rojas. 1985. Glucoseinduced oscillatory changes in extracellular ionized potassium concentration in mouse islets of Langerhans. Biophys. J. 48:741-749.

11. Orci, L., and R. H. Unger. 1975. Functional subdivision of islets of Langerhans and possible role of D-cells. Lancet. 2:1243-1244.

12. Salomon, D., and P. Meda. 1986. Heterogeneity and contactdependent regulation of hormone secretion by individual B cells. Exp. Cell Res. 162:507-520.

13. Orci, L., D. Baetens, M. Ravazzola, Y. Stefan, and F. MalaisseLagae. 1976. Pancreatic polypeptide and glucagon: non-random distribution in pancreatic islets. Life Sci. 19:1811-1816.

14. Berthoud, H.-R., W. B. Laughton, and T. L. Powley. 1986. A method for large volume blood sampling and transfusion in rats. Am. J. Physiol. 250:E331-E337. 
15. Lacy, P. E., and M. Kostianovski. 1967. Method for the isolation of intact islets of Langerhans from the rat pancreas. Diabetes. 16:35-39.

16. Shibata, A., C. W. Ludvigsen, S. P. Naher, M. L. McDaniel, and P. E. Lacy. 1976. Standardization of a digestion-filtration method for the isolation of pancreatic islets. Diabetes. 25:667-672.

17. Baetens, D., Y. Stefan, M. Ravazzola, F. Malaisse-Lagae, D. L. Coleman, and L. Orci. 1978. Alteration of islet cell populations in spontaneously diabetic mice. Diabetes. 27:1-7.

18. Weibel, E. R. 1979. Stereological Methods. Academic Press, London. Vol. 1. 415.

19. Loubatière, A., M. M. Mariani, G. Ribes, H. de Malbosc, and J. Chapal. 1969. Etude experimentale d'un nouveau sulfamide hypoglycemiant particulièrement actif, le HB419 ou glibenclamide. I. Action betacytotrope et insulinosécrétrice. Diabetologia. 5:1-10.

20. Logothetopoulos, J., M. Kaneko, G. A. Wrenshall, and C. H. Best. 1964. Zinc, granulation and extractable insulin of islet cells following hyperglycemia or prolonged treatment with insulin. In Structure and Metabolism of the Pancreatic Islets. S. E. Brolin and B. Hellman, editors. Pergamon Press, Oxford. 333-347.

21. Leahy, J. L., H. E. Cooper, D. A. Deal, and G. C. Weir. 1986. Chronic hyperglycemia is associated with impaired glucose influence on insulin secretion. J. Clin. Invest. 77:908-915.

22. Logothetopoulos, J., and K. Jain. 1980. In vivo incorporation of ${ }^{3} \mathrm{H}$-leucine ${ }^{3} \mathrm{H}$-tryptophan into proinsulin-insulin and other islet cell proteins in normoglycemic, hyperglycemic and hypoglycemic rats. Diabetes. 29:801-805.

23. Zucker, P., and J. Logothetopoulos. 1975. Persisting enhanced proinsulin-insulin and protein biosynthesis $\left({ }^{3} \mathrm{H}\right.$-leucine incorporation) by pancreatic islets of the rat after glucose exposure. Diabetes. 24:194200.

24. Logothetopoulos, J., and N. Valiquette. 1984. Hormonal and non-hormonal protein biosynthesis in the pancreatic beta cell of the intact rat after prolonged hyperglycaemia. Acta Endocrinol. 107:382389.

25. Trimble, E. R., and A. E. Renold. 1981. Ventral and dorsal areas of rat pancreas: islet hormone content and secretion. Am. J. Physiol. 240:E422-E427.

26. Trimble, E. R., P. A. Halban, C. B. Wollheim, and A. E. Renold. 1982. Functional differences between rat islet of ventral and dorsal pancreatic origin. J. Clin. Invest. 69:405-413.

27. Leclercq-Meyer, V., J. Marchand, and W. J. Malaisse. 1985. In- sulin and glucagon release from the ventral and dorsal parts of the perfused pancreas of the rat. Horm. Res. (Basel). 21:19-32.

28. Meda, P., A. Perrelet, and L. Orci. 1984. Gap junctions and cellto-cell coupling in endocrine glands. Mod. Cell Biol. 3:131-196.

29. Fujita, T., Y. Yanatori, and T. Murakami. 1976. Insuloacinar axis, its vascular basis and its functional and morphological changes caused by CCK-PZ and caerulein. In Endocrine Gut and Pancreas. T. Fujita, editor. Elsevier Scientific Publishing, Amsterdam. 347-357.

30. Ohtani, O., T. Ushiki, H. Kanazawa, and T. Fujita. 1986. Microcirculation of the pancreas in the rat and rabbit with special reference to the insulo-acinar portal system and emissary vein of the islet. Arch. Histol. Jpn. 49:45-60.

31. Bonner-Weir, S., and L. Orci. 1982. New perspectives on the microvasculature of the islets of Langerhans in the rat. Diabetes. 31: 883-889.

32. Samols, E., S. Bonner-Weir, and G. C. Weir. 1986. Intra-ișlet insulin-glucagon-somatostatin relationships. Clin. Endocrinol. Metab. 15: 33-58.

33. Miller, R. E. 1981. Pancreatic neuroendocrinology: peripheral neural mechanisms in the regulation of the islets of Langerhans. Endocr. Rev. 2:471-494.

34. Forssmann, W. G., and J. Greenberg. 1978. Innervation of the endocrine pancreas in primates. In Peripheral Neuroendocrine Interactions. R. E. Coupland and W. G. Forssman, editors. Springer-Verlag, Berlin. 124-133.

35. Lundquist, I., and L. E. Ericson. 1978. $\beta$-Adrenergic insulin release and adrenergic innervation of mouse pancreatic islets. Cell Tissue Res. 193:73-85.

36. Grodsky, G. M. 1972. A threshold distribution hypothesis for packet storage of insulin and its mathematical modeling. J. Clin. Invest. 51:2047-2059.

37. Sando, H., J. Borg, and D. F. Steiner. 1972. Studies on the secretion of newly synthesized proinsulin and insulin from isolated rat islets of Langerhans. J. Clin. Invest. 51:1476-1485.

38. Gold, G., H. D. Landahl, M. L. Gishizky, and G. M. Grodsky. 1982. Heterogeneity and compartmental properties of insulin storage and secretion in rat islets. J. Clin. Invest. 69:554-563.

39. Halban, P. A. 1982. Differential rates of release of newly synthesized and of stored insulin from pancreatic islets. Endocrinology. 110: 1183-1188. 